\title{
Studies of Catalytic Properties of Inorganic Rock Matrices in Redox Reactions
}

\author{
Nikolay M. Dobrynkin"1, Marina V. Batygina ${ }^{2}$, Alexander S. Noskov ${ }^{3}$ \\ ${ }^{1}$ Department of Catalytic Process Engineering, Boreskov Institute of Catalysis, pr. Lavrentieva 5, \\ Novosibirsk, Russia \\ e-mail: dbn@catalysis.ru \\ ${ }^{2}$ Department of Catalytic Process Engineering, Boreskov Institute of Catalysis, pr. Lavrentieva 5, \\ Novosibirsk, Russia \\ e-mail: monolasta@gmail.com \\ ${ }^{3}$ Department of Catalytic Process Engineering, Boreskov Institute of Catalysis, pr. Lavrentieva 5, \\ Novosibirsk, Russia \\ e-mail: noskov@catalysis.ru
}

Cite as: Dobrynkin, N. M., Batygina, M. V., Noskov, A. S., Studies of Catalytic Properties of Inorganic Rock Matrices in Redox Reactions, J. sustain. dev. energy water environ. syst., 5(3), pp 408-416, 2017, DOI: http://dx.doi.org/10.13044/j.sdewes.d5.0151

\begin{abstract}
Intrinsic catalytic properties of mineral matrices of various kinds (basalts, clays, sandstones) were studied, which are of interest for in-situ heavy oil upgrading (i.e., underground) to create advanced technologies for enhanced oil recovery. The elemental, surface and phase composition and matrix particle morphology, surface and acidic properties were studied using elemental analysis, X-ray diffraction, adsorption and desorption of nitrogen and ammonia. The data on the catalytic activity of inorganic matrices in ammonium nitrate decomposition (reaction with a large gassing), oxidation of hydrocarbons and carbon monoxide, and hydrocracking of asphaltenes into maltenes (the conversion of heavy hydrocarbons into more valuable light hydrocarbons) were discussed. In order to check their applicability for the asphaltenes hydrocracking catalytic systems development, basalt and clay matrices were used as supports for iron/basalt, nickel/basalt and iron/clay catalysts. The catalytic activity of the matrices in the reactions of the decomposition of ammonium nitrate, oxidation of hydrocarbons and carbon monoxide, and hydrocracking of asphaltens was observed for the first time.
\end{abstract}

\section{KEYWORDS}

Oil-bearing rock matrices, Oil production stimulation, High-viscosity oil, Asphaltenes, Hydrocracking, Decomposition of ammonium nitrate, Catalytic processes in-situ.

\section{INTRODUCTION}

At present, fundamental studies in the area of stimulation of oil production from deep horizons are of ever increasing importance. A progressive decrease in oil recovery and an increase in the unit costs per ton of extracted oil are characteristic of many currently operated oil fields worldwide. In an overwhelming majority of countries, the oil recovery is no more than $25-40 \%$ and tends to decrease. Three main stages are classified in the oil field practice. In the first stage, the natural energy of the reservoir is used (super pressure,

\footnotetext{
* Corresponding author
} 
gas solute energy, etc.). In the second stage, the oil recovery is stimulated by injecting water or gas into the bed. In the third stage, various Advanced Oil Recovery Methods (AORM) are used, including heat, gas, hydrodynamic, physical and chemical techniques.

Great attention is paid in developed countries to the improvement of existing and development of new methods for controlling oil recovery. In 2016, there were 365 projects in the world, which dealt with methods for enhancing oil recovery [1]. It was accepted that the heat (15-30\% increased oil recovery factor) and chemical (25-35\% increased oil recovery factor) methods are most efficient for traditional medium-viscous oil fields. A gas injection technique [Carbon dioxide $\left(\mathrm{CO}_{2}\right)$, Nitrogen $\left(\mathrm{N}_{2}\right)$, natural gas or flue gas] historically used for light oil recovery now has become the technology of choice for unconventional reservoirs [2]. Thermal injection techniques such as cyclic steam stimulation, steam flooding and steam-assisted gravity drainage are widely used in the world for oil recovery in heavy oil reservoirs because their primary means is reduction in crude viscosity [3]. However, these and other currently available AORM [4] are inefficient, cost demanding and ecologically unfavourable methods when used for the recovery of high-viscous, heavy and ultra heavy oil.

As an alternative option, the catalytic conversion of heavy oil and non-traditional hydrocarbon compounds directly in the oil field should be considered.

The in-situ catalytic upgrading process using a catalyst added in the production well and combined with air injection (now the THAI- CAPRI process) for the extraction and upgrading of heavy oil and bitumen downhole was first described in [5]. More recent studies have shown the potential for rapid catalyst deactivation due to coke and metal deposits during the catalytic upgrading and possibilities to overcome the challenges of coke deposits by addition of hydrogen or a hydrogen donor [6]. In addition to the above methods, another promising direction is the use of sub-micron catalysts for chemical processes to upgrade heavy oil and bitumen in-situ [7].

Recently another promising method of stimulating oil recovery by the reactions with intensive gas emission (so called binary mixtures method) was suggested for the formation of pressure drainage in the bed and artificial gas lift in the well [8].

These economically and ecologically attractive approaches to enhance oil recovery imply simultaneous in-field temperature elevation and an introduction of nanosized catalysts into the field. In our current research, the use the intrinsic catalytic properties of the inorganic matrix of oil-bearing rocks was suggested. It was applied to:

- Synthesize in-situ active catalytic systems;

- Synthesize nanosized clusters of active components on natural inorganic matrices by injecting the precursors into the field;

- Catalyze transformations of heavy oil hydrocarbon components;

- Catalyze different chemical reactions, for example, the reactions with intensive gas emission (decomposition of ammonium nitrate and like compounds).

At present, data on the catalytic activity of oil-bearing rock matrices of various kinds (basalts, clays, sandstones) towards the decomposition of ammonium nitrate and the oxidation of hydrocarbons and carbon monoxide are completely absent in the literature.

Then, according to the Russian Federation National Program of "Environment Protection" for the period of 2012-2020, the intensification of oil extraction from deep horizons is particularly relevant for the solution of the environmental problems associated with the deposits of heavy oil and bituminous rocks in the Siberian region of Russia. Principles of green technologies are extremely important, not only for regions of Russia [9], but for other countries in the world as well [10].

Therefore, the studies of physicochemical and catalytic properties of oil-bearing rock matrices are essential in understanding the physical and chemical processes in oil reservoirs under simultaneous heat and chemical action, and to handle technological problems for stimulation of oil recovery. 


\section{EXPERIMENTAL}

$\mathrm{X}$-ray diffraction (Bruker D8 diffractometer with monochromatic $\mathrm{CuK} \alpha$ radiation) and X-ray fluorescent (VRA-30 instrument with Cr-anode of the X-ray tube) techniques were used to study the elemental composition of oil-bearing rock matrices of different types (sand rocks, clays, basalts). The single BET method was used for the determination of surface areas and pore volumes by one-point nitrogen adsorption at $77 \mathrm{~K}$ by the ASAP-2020 instrument.

Catalytic activities to oxidation of methane and carbon monoxide were measured using a flow reactor at $623-873 \mathrm{~K}$ with the initial component concentrations of $1.0 \mathrm{vol} . \%$ methane, 10 vol.\% oxygen (mixture \#1), 0.88 vol.\% carbon monoxide, 1.32 vol.\% oxygen (mixture \#2) in nitrogen; catalyst sample of $1 \mathrm{~g}$; and flow rate of $2.4 \mathrm{~L} / \mathrm{h}$. A Kristall 5000 chromatograph was used for analysis of the initial gas mixtures.

The decomposition of ammonium nitrate was studied at 313-363 K using a thermostatic reactor equipped with a reflux condenser. The working solution was prepared just before the experiment by mixing calculated quantities of Ammonium nitrate $\left(\mathrm{NH}_{4} \mathrm{NO}_{3}\right)$, Formic acid $(\mathrm{HCOOH})$ and Nitric acid $\left(\mathrm{HNO}_{3}\right)$ in water. Total solution volume was $50 \mathrm{ml}$. A magnetic stirrer was used for the reaction mixture. Samples of the working solution were drawn to determine the concentration of $\mathrm{NH}_{4} \mathrm{NO}_{3}$. Current concentrations of ammonium ions in the working solutions were determined using a universal ionometer EV-74 equipped with an ion-selective electrode ELIS $121 \mathrm{NH}_{4}$. A silver chloride electrode $1 \mathrm{M} 3$ was used as a reference. The total reaction run was 5 hours. The known industrial aluminoplatinum AP-56 [0.56\% platinum/gamma alumina $\left(\mathrm{Pt} / \gamma-\mathrm{Al}_{2} \mathrm{O}_{3}\right), 0.5 \mathrm{~g}$ ] catalyst/and three types of matrices of oil-bearing rocks (sand rock, basalt and clay) were used for the reaction.

The catalytic activity to hydrocracking of hydrocarbon components of oil was studied using asphaltene [the product of Vacuum Distillation Unit (VDU) tar extraction produced at the Gazpromneft-Omsk Refinery Co.; the content of n-pentane-insoluble but toluene-soluble asphaltenes was $96 \mathrm{wt} . \%$ ] as the initial compound. A micro reactor system Autoclave Engineering $(50 \mathrm{ml}$ reactor made of a chemically stable alloy Hastelloy ${ }^{\circledR}$ C-276, a magnetic stirrer with controlled rotary speed up to 5,000 rpm) was used for experiments at $1.0 \mathrm{MPa}$ hydrogen pressure and 473, 523 and $573 \mathrm{~K}$ temperatures. The gravimetric method was used to determine masses of toluene-soluble (asphaltenes) and n-heptane-soluble (maltenes) fractions. The catalysts were natural material matrices and supported catalysts such as Iron (Fe)/basalt matrix, Nickel (Ni)/basalt matrix and Fe/clay matrix ( $6.0 \mathrm{wt} . \%$ of active component) prepared by the precipitation from non-aqueous solutions of the corresponding nitrate followed by the calcining and activation at $773 \mathrm{~K}$.

\section{RESULTS AND DISCUSSION}

Table 1 summarizes the XRD and XRF data (Figure 1), specific surface areas $\left(S_{\mathrm{BET}}\right)$ and pore volumes of matrices. The analysis of experimental data on elemental composition suggests that the matrix samples are natural aluminosilicates with numerous impurities. For example, characteristic features of basalt and clay matrices are significant amounts of transition and alkaline earth element oxides [2.75-3.3 wt.\% Fe, 0.3-0.4 wt.\% Titanium (Ti), 7.2-1.4 wt.\% Magnesium (Mg)] and large surface areas $\left(25-15 \mathrm{~m}^{2} / \mathrm{g}\right)$ that are sufficient for catalysis on the surface.

One of the factors that determine the catalytic activity of the catalyst is the specific surface area, which affects the amount and availability of the active centers. The specific surface area among the samples (see Table 1) is the highest in the clay matrix and the lowest in the sandstone matrix. Analysis of the surface area and pore distribution of the samples indicates that basically all the matrices are mesoporous. 
It was found that the differences in the chemical composition and texture are the reasons for different catalytic activities of the matrices both to the transformation of oil hydrocarbon components and to the liquid-phase decomposition of ammonium nitrate.

Table 1. Physicochemical parameters of samples under study

\begin{tabular}{|c|c|c|c|c|c|c|c|c|c|c|}
\hline \multirow{2}{*}{ Matrix } & \multicolumn{8}{|c|}{ Content of elements [wt.\%] } & \multirow{2}{*}{$\begin{array}{c}S_{\mathrm{BET}} \\
{\left[\mathrm{m}^{2} / \mathrm{g}\right]}\end{array}$} & \multirow{2}{*}{$\begin{array}{c}V_{\mathrm{p}} \\
{[\mathrm{ml} / \mathrm{g}]}\end{array}$} \\
\hline & $\mathrm{Li}-\mathrm{F}$ & $\mathrm{Si}$ & $\mathrm{Mg}$ & $\mathrm{Al}$ & K & $\mathrm{Fe}$ & $\mathrm{Na}$ & $\mathrm{Ti}$ & & \\
\hline Bazalt & 65.01 & 13.53 & 7.20 & 6.35 & 0.20 & 2.74 & 0.73 & 0.33 & 19 & 0.0431 \\
\hline Clay & 56.76 & 23.76 & 1.74 & 8.87 & 2.35 & 3.30 & 1.07 & 0.41 & 25 & 0.0634 \\
\hline \multirow[t]{2}{*}{ Sand } & 65.06 & 23.73 & 0.54 & 6.33 & 1.44 & 0.90 & 1.44 & 0.22 & 15 & 0.0141 \\
\hline & $\mathrm{Ca}$ & $\mathrm{S}$ & $\mathrm{P}$ & $\mathrm{Mn}$ & $\mathrm{Ba}$ & $\mathrm{Ce}$ & $\mathrm{Sr}$ & $\mathrm{Cl}$ & & \\
\hline Bazalt & 3.52 & - & 0.09 & 0.08 & - & - & 0.15 & - & 19 & 0.0431 \\
\hline Clay & 0.61 & 0.79 & 0.07 & 0.03 & 0.12 & 0.02 & 0.02 & - & 25 & 0.0634 \\
\hline Sand & 0.14 & 0.08 & 0.02 & - & 0.04 & - & - & 0.06 & 15 & 0.0141 \\
\hline
\end{tabular}

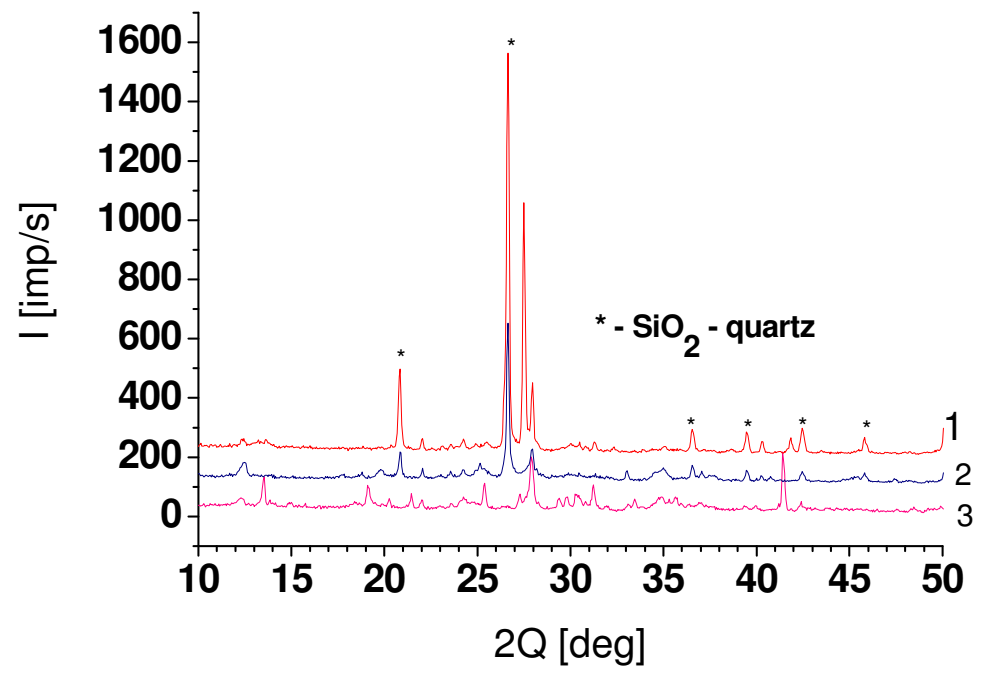

Figure 1. XRD patterns of samples under study (1 - sandstone matrix, 2 - clay matrix, 3 - basalt matrix)

\section{Ammonium nitrate decomposition}

Figure 2 shows the temperature dependence of $\mathrm{NH}_{4} \mathrm{NO}_{3}$ conversion in the absence of a catalyst. The degree of nitrate ammonium decomposition is high enough at $463 \mathrm{~K}$ (92.4\%). At low temperatures $(313-324 \mathrm{~K})$ the value of $\mathrm{NH}_{4} \mathrm{NO}_{3}$ conversion does not exceed $13 \%$. Addition of a catalyst to the reaction mixture allows the decomposition degree to increase by factors of 3 to 4 (Figure 3). At $324 \mathrm{~K}$ the conversion is $39.7 \%$ over $\mathrm{Pt} / \gamma-\mathrm{Al}_{2} \mathrm{O}_{3}, 52.2 \%$ over sandstone matrix, $47.5 \%$ over basalt matrix, and $46.3 \%$ over clay matrix.

The dependence of the conversion of ammonium nitrate over the sandstone matrix as a function of component ratio was studied at $324 \mathrm{~K}$. A linear dependence of the conversion with an increase of nitric acid concentration at the ratio of $\mathrm{HNO}_{3}: \mathrm{HCOOH}=1$ was observed (Figures 4, 5). The dependence of the degree of $\mathrm{NH}_{4} \mathrm{NO}_{3}$ decomposition as a function of nitric to formic acid ratio had maximum at $\mathrm{HNO}_{3}: \mathrm{HCOOH}=2.7$, and the maximum was identical when different mixtures were used. At maximum the ammonium nitrate conversions were 88, 59.1 and $19 \%$ at $\mathrm{HNO}_{3}: \mathrm{NH}_{4} \mathrm{NO}_{3}=12,7$ and 4, respectively. 


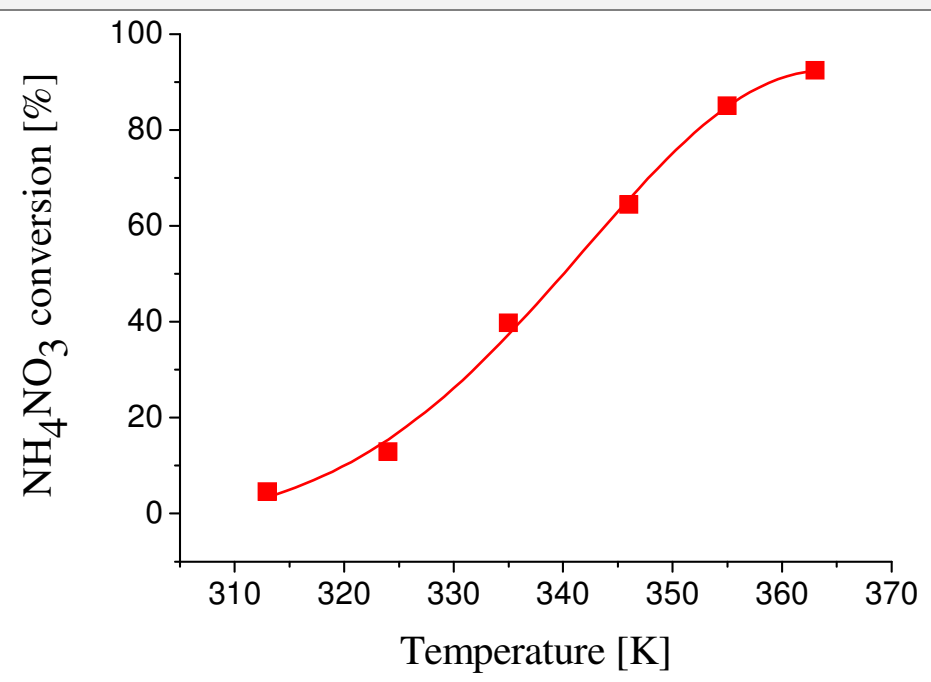

Figure 2. Temperature dependence of $\mathrm{NH}_{4} \mathrm{NO}_{3}$ conversion in the absence of a catalyst

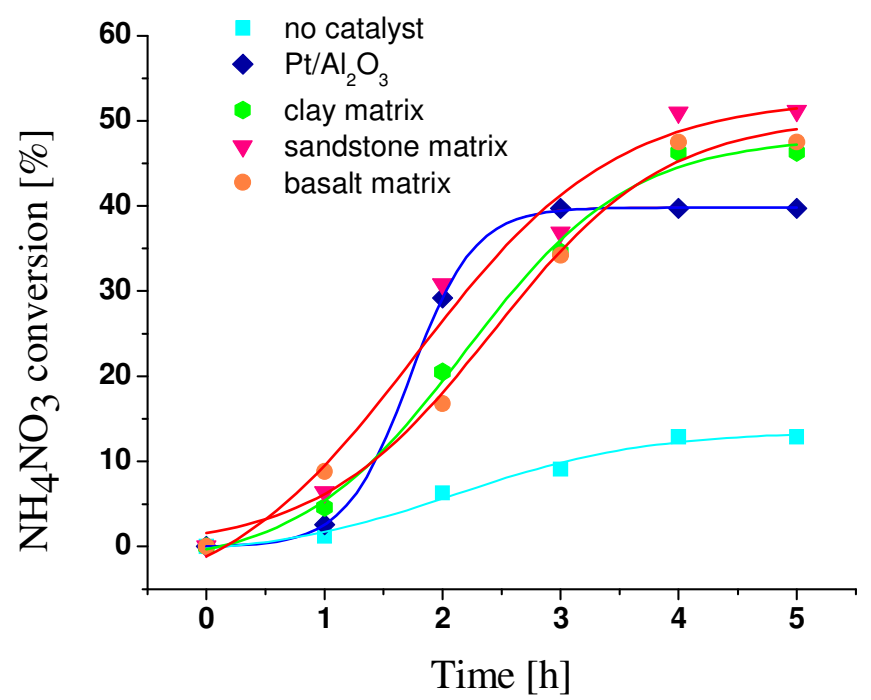

Figure 3. Ammonium nitrate conversion in presence of rock matrices and $\mathrm{Pt} / \mathrm{Al}_{2} \mathrm{O}_{3}$ catalyst (the ratio $\mathrm{HNO}_{3}: \mathrm{HCOOH}: \mathrm{NH}_{4} \mathrm{NO}_{3}=7.8: 3.4: 1, \mathrm{HNO}_{3}: \mathrm{HCOOH}=2.3, T=324 \mathrm{~K}$ )

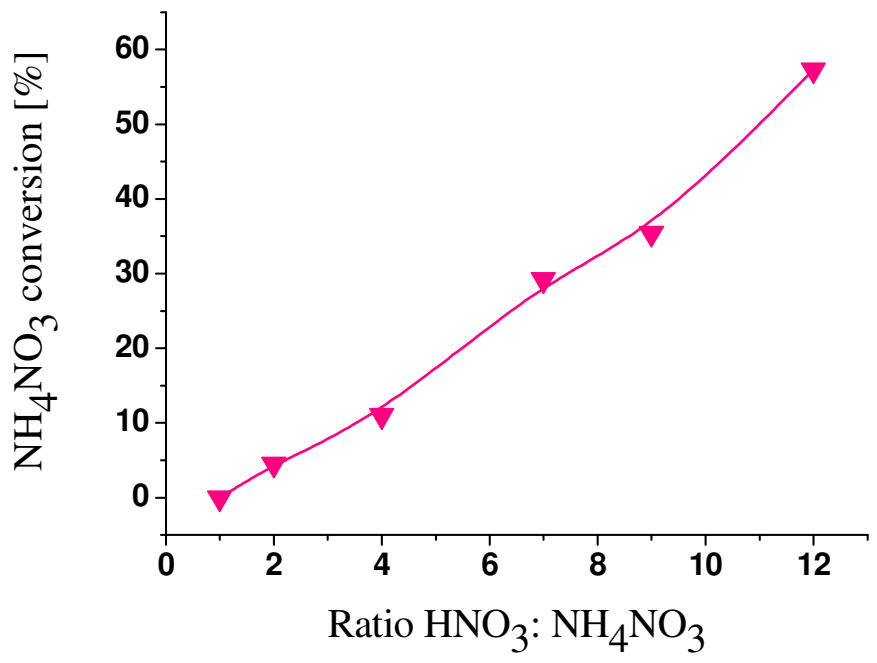

Figure 4. Dependence of the conversion of ammonium nitrate on molar ratio of nitric acid and ammonium nitrate

$\left(T=324 \mathrm{~K}, m=0.5 \mathrm{~g}\right.$ of sandstone matrix, reaction time $5 \mathrm{~h}$, the ratio $\left.\mathrm{HNO}_{3}: \mathrm{HCOOH}=1\right)$ 


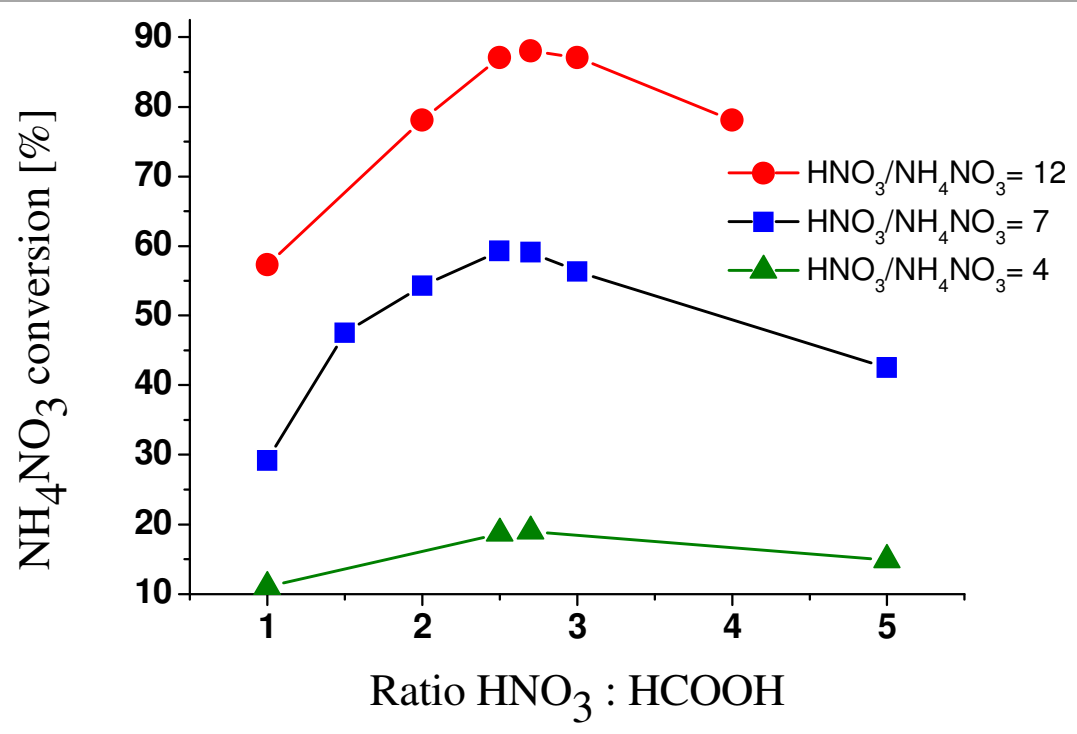

Figure 5. Dependence of the conversion of ammonium nitrate on component molar ratio $(T=324 \mathrm{~K}, m=0.5 \mathrm{~g}$ of sandstone matrix, reaction time $5 \mathrm{~h}$ )

Based on the literature review [11] and experimental data, it is reasonable to suggest that the decomposition of ammonium nitrate in water is associated with the oxidation by Nitrous acid $\left(\mathrm{HNO}_{2}\right)$ :

$$
\mathrm{NH}_{4} \mathrm{NO}_{3}+\mathrm{HNO}_{2} \rightarrow \mathrm{N}_{2}+\mathrm{HNO}_{3}+2 \mathrm{H}_{2} \mathrm{O}
$$

Nitrous acid is generated by the $\mathrm{HNO}_{3}-\mathrm{HCOOH}$ system where Nitric oxide (NO) and Nitrogen dioxide $\left(\mathrm{NO}_{2}\right)$ are produced through the following reactions [12]:

$$
\begin{gathered}
2 \mathrm{HNO}_{3}+\mathrm{HCOOH} \rightarrow 2 \mathrm{NO}_{2}+\mathrm{CO}_{2}+2 \mathrm{H}_{2} \mathrm{O} \\
2 \mathrm{HNO}_{3}+2 \mathrm{HCOOH} \rightarrow \mathrm{NO}+\mathrm{NO}_{2}+2 \mathrm{CO}_{2}+3 \mathrm{H}_{2} \mathrm{O} \\
2 \mathrm{HNO}_{3}+3 \mathrm{HCOOH} \rightarrow 2 \mathrm{NO}+3 \mathrm{CO}_{2}+4 \mathrm{H}_{2} \mathrm{O}
\end{gathered}
$$

The released nitrogen (IV) and nitrogen (II) oxides react with water to produce nitrous acid by the following reactions [13]:

$$
\begin{aligned}
& 2 \mathrm{NO}_{2}+\mathrm{H}_{2} \mathrm{O} \leftrightarrow \mathrm{HNO}_{3}+\mathrm{HNO}_{2} \\
& 2 \mathrm{NO}+\mathrm{HNO}_{3}+\mathrm{H}_{2} \mathrm{O} \leftrightarrow 3 \mathrm{HNO}_{2}
\end{aligned}
$$

\section{Oxidation of Carbon monoxide (CO) and Methane $\left(\mathrm{CH}_{4}\right)$}

A flow reactor was used to study catalytic activities of the samples for the oxidation of methane [known to be the most resistant to the oxidation among aliphatic hydrocarbons (Table 2)], and carbon monoxide (Figure 6). Basalt samples were the most catalytically active and sandstones were the least active among all catalysts studied. The conversion was relatively low comparing to others deliberately developed catalysts: within the temperature range under study in the presence of the most active matrix (basalt), the conversion of carbon monoxide was $18 \%$ and conversion of methane was $21 \%$. 
Table 2. Catalytic activity of matrices in deep oxidation of $\mathrm{CH}_{4}$

$\left(C_{\mathrm{CH}_{4}}=1.0\right.$ vol. $\%, C_{\mathrm{O}_{2}}=10.0$ vol. $\%, C_{\mathrm{N}_{2}}=89.0 \mathrm{vol} . \%, m_{\text {cat }}=1 \mathrm{~g}$, mixture flow rate $\left.=2.4 \mathrm{l} / \mathrm{h}\right)$

\begin{tabular}{ccccc}
\hline & & \multicolumn{3}{c}{$\mathrm{CH}_{4}$ conversion [\%] } \\
\cline { 3 - 5 } No. & $T[\mathrm{~K}]$ & \multicolumn{3}{c}{ Matrix samples } \\
\cline { 3 - 5 } & & Basalt & Clay & Sandstone \\
\hline 1. & 623 & 5.3 & 6.0 & 4.8 \\
2. & 673 & 4.7 & 5.9 & 4.9 \\
3. & 723 & 6.1 & 5.6 & 4.2 \\
4. & 773 & 6.7 & 5.0 & 4.5 \\
5. & 823 & 11.3 & 4.8 & 4.6 \\
6. & 873 & 21.1 & 11.1 & 5.1 \\
\hline
\end{tabular}

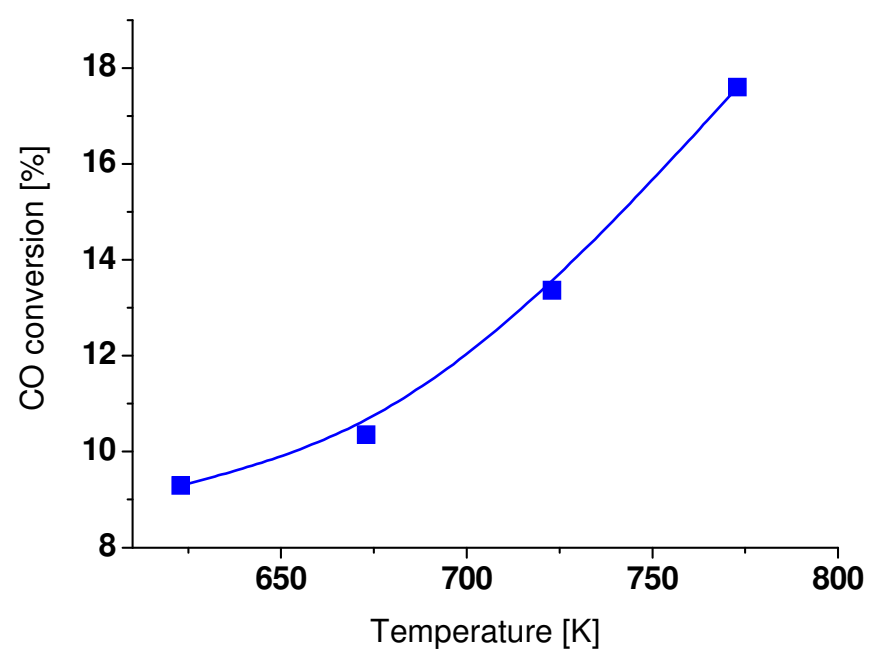

Figure 6. Temperature dependence of the conversion of carbon monoxide oxidized in a flow reactor in the presence of basalt matrix

$\left(C_{\mathrm{CO}}=0.88 \mathrm{vol} . \%, C_{\mathrm{O}_{2}}=1.32 \mathrm{vol} . \%, C_{\mathrm{N}_{2}}=97.8 \mathrm{vol} . \% ., m_{\mathrm{cat}}=1 \mathrm{~g}\right.$, mixture flow rate $\left.=2.4 \mathrm{l} / \mathrm{h}\right)$

\section{Asphaltenes hydrocracking}

Of special interest are catalytic properties of rock matrices with respect to hydrocracking of heavy oil components - asphaltenes to maltenes. Table 3 shows experimental data on the intrinsic activities of matrix samples and on the activities of supported $\mathrm{Fe}$ - and $\mathrm{Ni}$-containing catalysts. The data indicate negligible activity of sandstone-based samples, while clay-based and, in particular, basalt-based samples demonstrate considerable catalytic activity to hydrocracking of asphaltenes. Again, the highest selectivity to maltenes was observed with basalt samples and iron-nickel catalysts supported on basalt. The activity and selectivity series of the matrix samples are as follows: $6 \% \mathrm{Fe} /$ clay matrix $<6 \% \mathrm{Ni} /$ basalt matrix $<6 \% \mathrm{Fe} /$ basalt matrix. The estimations based on thermodynamic data [14] show an absolute conversion of $25-30 \%$ of the theoretically allowable levels under current experimental conditions (temperature range of 473-573 K, hydrogen pressure 1.0 MPa). The highest conversions of asphaltenes $(\mathrm{X}>95 \%)$ at the one-stage process are achieved, in fact, at the pressure of $30 \mathrm{MPa}$ [15].

The observed trends in the catalytic activity of the sample matrix for various reactions can be explained by the differences in their chemical nature. In fact, as can be seen from the above data, sample matrixes are natural aluminosilicates with different impurities. Samples from basalt matrix and clays are characterized by the presence of significant amounts of oxides of transition and alkaline earth elements $(\mathrm{Fe}, \mathrm{Ti}, \mathrm{Mg})$ in their structure, specific surface areas $\left(25-15 \mathrm{~m}^{2} / \mathrm{g}\right)$ sufficient for catalytic reactions on the surface. Samples of sandstones matrices, in contrast, have low surface areas. They are 
characterized by a low amount of elements such as magnesium, iron, manganese, and by the total absence of cerium containing compounds which are known to be strong promoters of catalytic activity of various catalytic systems.

Table 3. Catalytic activity to hydrocracking [Conversion of asphaltenes/selectivity to maltenes $(\%)$, in an autoclave reactor at $473,523,573 \mathrm{~K}$, catalyst weight $=1.0 \mathrm{~g}$, asphaltene loading $=10 \mathrm{~g}$, hydrogen pressure $=1.0 \mathrm{MPa}$, reaction time $=1 \mathrm{~h}]$

\begin{tabular}{ccccc}
\hline \multirow{2}{*}{ No. } & \multirow{2}{*}{ Matrix samples } & \multicolumn{3}{c}{$T[\mathrm{~K}]$} \\
\cline { 3 - 5 } & & 473 & 523 & 573 \\
\hline 1 & Blanc & - & $<1.0 / 0.01$ & $3.0 / 0.01$ \\
2 & Basalt & $3.0 / 0.1$ & $5.1 / 8.3$ & $7.1 / 11$ \\
3 & Clay & - & $<3.0 / 0.01$ & $5.0 / 8.0$ \\
4 & Sandstone & - & - & $<3.0 / 0.01$ \\
5 & $6 \%$ Fe/basalt & $4.2 / 4.0$ & $7.1 / 9.3$ & $9.7 / 15$ \\
6 & $6 \%$ Fe/clay & $3.3 / 3.2$ & $4.5 / 7.3$ & $7.4 / 12$ \\
7 & $6 \%$ Ni/basalt & $3.8 / 3.8$ & $6.4 / 11$ & $7.5 / 14$ \\
\hline
\end{tabular}

These differences in the sample chemical compositions and surface characteristics are responsible for different catalyst matrices activity in reactions of hydrocarbon conversion of petroleum components (oxidation of methane and butane, hydrocracking of heavy components - asphaltenes) where a critical role in catalysis is the formation of surface compounds - active complexes. The influence of homogeneous catalysts in liquid phase ammonium nitrate decomposition reactions is significant. Therefore it is likely that the high catalytic activity of matrices may be associated with presence of soluble compounds which catalyze the decomposition of ammonium nitrate.

The use of natural materials served as carriers for supported catalysts (Fe/basalt, and $\mathrm{Ni} /$ basalt and Fe/clay matrixes), was found to be a promising line of research in conversion of hydrocarbon components of oil.

\section{CONCLUSIONS}

The study presents data on physicochemical and structural properties of matrix samples (chemical composition, specific surface area and pore volume), their catalytic activities in the oxidation and hydrocracking of oil hydrocarbon components. The natural oil-bearing rocks studied were found to be more catalytic-active in the decomposition of ammonium nitrate than the industrial Pt/alumina catalyst.

The experimental data support the hypothesis about the feasibility of catalytic reactions in oil beds using natural materials - oil-bearing rocks (sandstones, clays, basalts) - as catalysts and can be helpful for the development of advanced technologies for enhanced oil recovery.

The reported results are considered to be the basis for future studies of mineral matrices in the development of effective catalysts for in-situ treatment of heavy hydrocarbons in oil industry.

\section{ACKNOWLEDGEMENT}

The authors are grateful to the Russian Scientific Foundation for the financial support (Project 15-13-00057).

\section{REFERENCES}

1. Sandrea, R. and Dharod, D., Approach Screens Reservoir Candidates for EOR, Oil \& Gas Journal, Vol. 114, No. 4, pp 48-52, 2016. 
2. Lake, L. W., Johns, R. T., Rossen, B. and Pope, G., Fundamentals of Enhanced Oil Recovery, Richardson, TX: Society of Petroleum Engineers, 2014.

3. Shah, A., Fishwick, R., Wood, J., Leeke, G., Rigby, S. and Greaves, M., A Review of Novel Techniques for Heavy Oil and Bitumen Extraction and Upgrading, Energy \& Environmental Science, Vol. 3, No. 6, pp 700-714, 2010, https://doi.org/10.1039/b918960b

4. Weisman, J. G. and Kessler, R. V., Downhole Heavy Crude Oil Hydroprocessing, Appl. Catal., Vol. 140, No. 1, pp 1-16, 1996, https://doi.org/10.1016/0926-860X(96)00003-8

5. Weissman, J. G., Kessler, R. V., Sawicki, R. A., Belgrave, J. D. M., Laureshen, C. J., Metha, S. A., Moore, R. G. and Ursenbach, M. G., Down-hole Catalytic upgrading of Heavy Crude Oil, Energy \& Fuels, Vol. 10, No. 4, pp 883-889, 1996, https://doi.org/10.1021/ef9501814

6. Hart, A., Leeke, G., Greaves, M. and Wood, J., Downhole Heavy Crude Oil upgrading using CAPRI: Effect of Steam upon Upgrading and Coke Formation, Energy $\quad \& \quad$ Fuels, $\quad$ Vol. 28, No. 3, pp 1811-1819, 2014, https://doi.org/10.1021/ef402300k

7. Galarraga, C. E. and Pereira-Almao, P., Hydrocracking of Athabasca Bitumen using Submicronic Multimetallic Catalysts at Near In-reservoir Conditions, Energy Fuels, Vol. 24, No. 4, pp 2383-2389, 2010, https://doi.org/10.1021/ef9013407

8. Aleksandrov, E. N., Kuznetsov, N. M., Lunin, V. V., Lemenovskii, D. A., Merzhanov, A. G., Petrov, A. L. and Lidzhi-Goryaev, V. Yu., An Evaluation of a Thermochemical Technique for Increasing the Productivity of Oil-bearing Beds and Reduction of Oil-Deposit Watering Based on Reactions of Binary Mixtures, Russian Journal of Physical Chemistry B, Vol. 7, No. 7, pp 802-809, 2013, https://doi.org/10.1134/S1990793113070026

9. Pakina, A. A., Green Economy's Prospects in Russia: Case of Baikal Area, Journal of Sustainable Development of Energy, Water and Environment Systems, Vol. 2, No. 2, pp 139-151, 2014, https://doi.org/10.13044/j.sdewes.2014.02.0013

10. Arakawa, J. and Akimoto, K., Assessment of the Japanese Energy Efficiency Standards Program, Journal of Sustainable Development of Energy, Water and Environment Systems, Vol. 3, No. 1, pp 66-78, 2015, https://doi.org/10.13044/j.sdewes.2015.03.0005

11. Savara, A., Li, M-J., Sachtler, W. M. H. and Weitz, E., Catalytic Reduction of $\mathrm{NH}_{4} \mathrm{NO}_{3}$ by NO: Effects of Solid Acids and Implications for Low Temperature DeNO $_{x}$ Processes, Appl. Catal. B, Vol. 81, No. 3-4, pp 251-257, 2008, https://doi.org/10.1016/j.apcatb.2007.12.008

12. Vandegrift, G. F., Technical Report ANL-00/25, 2000, http://www.ipd.anl.gov/anlpubs/2000/12/38162.pdf, [Accessed: 27-August-2016]

13. Nova, I., Ciardelli, C., Tronconi, E., Chatterjee, D. and Weibel, M., $\mathrm{NH}_{3}-\mathrm{NO} / \mathrm{NO}_{2}$ SCR for Diesel Exhausts after Treatment: Mechanism and Modelling of a Catalytic Converter, Topics in Catalysis, Vol. 42-43, No. 1-4, pp 43-46, 2007, https://doi.org/10.1007/s11244-007-0148-4

14. Pereira-Almao, P., In Situ upgrading of Bitumen and Heavy Oils via Nanocatalysis, Can. J. Chem. Eng., Vol. 90, No. 2, pp 320-329, 2012, https://doi.org/10.1002/cjce.21646

15. Langlois, G. E. and Sullivan, R. F., Chemistry of Hydrocracking, Refining Petroleum for Chemicals, Chapter 3, Advances in Chemistry, Vol. 97, pp 38-67, 1970, https://doi.org/10.1021/ba-1970-0097.ch003 